\title{
Effect of Self-Esteem on the Relationship between Depression and Bullying among Teenagers in Malaysia
}

\author{
Ikechukwu Uba \\ Department of Human Development \& Family Studies \\ Faculty of Human Ecology, University of Putra Malaysia (UPM), Malaysia \\ E-mail: ubaikechukwu@yahoo.com \\ Siti Nor Yaacob \\ Department of Human Development \& Family Studies \\ Faculty of Human Ecology, University of Putra Malaysia (UPM), Malaysia \\ E-mail: sitinor@putra.upm.edu.my \\ Rumaya Juhari \\ Department of Human Development \& Family Studies \\ Faculty of Human Ecology, University of Putra Malaysia (UPM), Malaysia \\ E-mail: rumaya@putra.upm.edu.my \\ Mansor Abu Talib \\ Department of Human Development \& Family Studies \\ Faculty of Human Ecology, University of Putra Malaysia (UPM), Malaysia \\ E-mail: mansorat@gmail.com
}

\begin{abstract}
The study examined the moderating role of self-esteem in the relationship between depression and bullying among teenagers. The participants of the study were 242 teenagers aged 13 to 16 years, from selected secondary schools in Selangor, Malaysia. Self-esteem was measured with the Rosenberg Self-Esteem Scale, while teenage depression was measured with the Children Depression Inventory and bullying was measured using the Bully sub scale of the Peer Relationship Questionnaire. Findings of the study indicate no gender differences between males and females in self-esteem. The study further found a negative and medium correlation between depression and self- esteem, self-esteem and bullying and a positive and small correlation between depression and bullying. However, results of the study did not find self-esteem as a moderator. Recommendations of the study highlight the need to explore other variables such as religious and sports involvements as possible moderators in future studies.
\end{abstract}

Keywords: Self-esteem, Depression, Bullying, Teenagers

\section{Introduction}

Researchers in human development have long been interested in peer relationship and aggression among teenagers (Berger, 2007). In line with this lingering interest, recent studies have suggested that school bullying is a problematic behavior among adolescents. It has also been found to affect school achievement, pro-social skills, and the psychological well-being of both bullies and their victims (Boulton, Trueman, \& Murray, 2008). Earlier studies revealed that the experience of being bullied correlated with anxiety, depression, and low self-esteem (Hawker, \& Boulton, 2000). More so, recently emerging studies equally indicated that bullied children were significantly more likely to report not sleeping well, bed wetting, feeling sad, and experience of head and stomach aches (Monks, Smith, Naylor, Barter, \& Ireland, et al., 2009). Stauffacher and DeHart (2006) contend that peers become particularly important sources of influence during middle primary school years (Stauffacher, 
\& DeHart, 2006) and continue to be very influential throughout secondary school (Cunningham, Taylor, Whitten, Hardesty, \& Eder et al., 2010).

According to Maycock, Cross and Brown (2008) the interactions within peer groups influence bullying behaviors among school students. In view of the above, some scholars have argued in recent times that an adolescents' family environment and interactions can affect bullying behavior through diverse mechanisms (Spriggs, Iannotti, Nansel, \& Haynie2007). While others argue that adequate intervention to common risk and protective factors in late childhood may lead to the prevention of depression in adolescence (Roberts, Kane, Bishop, Cross, \& Fenton et al., 2010). Apparently, scholars in explaining the prevalence of bullying among teenagers have used various theoretical postulations. Attachment theory by Bowby (1982) is one of the theories. The theory hypothesized that the quality of attachment to parents/caregivers influences the development of an internal working model (IWM) of relationships, which impacts on how an individual related to others in his/her life (Main, Kaplan, \& Cassidy, 1985).

\section{Previous Research}

Some scholars have related insecure attachment with the involvement in bullying among children and adults (Monks, Smith, \& Swettenham, 2005). Aside attachment theory, other researchers that used social learning theory have argued that the impact of family variables on bullying behavior may be via modeling, with teenagers learning bullying behaviors through observation, role modeling, and reinforcement (Baldry, 2003). Twemlow and Fonagy (2005) provided further evidence for the impact of adult role models (both parents and teachers) on children's behavior. Available literatures have equally found that a significant number of teenage boys was involved in bullying in comparison to their female counterparts (Goldbaum, Craig, Pepler, \& Connolly 2007; Ivarsson, Broberg, Arvidsson, \& Gillberg, 2005). However, earlier studies have confirmed that physical bullying declines with age. Brame, Nagin and Tremblay (2001) found that other forms of bullying like verbal, relational and reactive bullies increase, with a sizable bump between ages 11 and 15 when children experience puberty and change schools (Archer, \& Cote, 2005; Espelage, Meban, \& Swearer, 2004).

Nonetheless, in the case of Malaysia, Yaakub and Leong (2007) revealed that cases of school bullying in the country has become a cause for concern. The study highlighted one of the appalling incidents of bullying, the brutal killing of a 16-year-old student by his school seniors in 2005. The incident according to the researcher raised public concern over violence in Malaysian schools, and the destructive role bullying plays among peers. Peer relationships are the most studied social determinants of bullying involvement, with the concepts of peer rejection and deviant affiliations prominently featured (Spriggs et al., 2007; Uba, Siti Nor, \& Rumaya, 2009). Scholars remain divided on bullies' self-worth. Olweus (1989) argues that bullies have high self- esteem, while O'Moore and Hillery (1991) contended that bullies have a low sense of worth. In variance, Rigley and Slee (1993) found no relationship between bullying and self-esteem. Therefore, whether the tendency to bully others was associated with small self respect, has remained unresolved. However, abundant evidence consistently supports the relationship between low self-esteem and depression (Scarpa, \& Luscher, 2002).

Conversely, it is possible that the relationship between self-esteem and depression is influenced by individual differences in response to uncontrollable stress (Scarpa, \& Luscher, 2002). Rosenberg (1965) argues that individuals, who respect themselves and considers themselves worthy, recognize their limitations and improve over time. In the view of McMullina and Cairney (2004) self-esteem is a socio-psychological construct that assesses an individual's attitude and perceptions of self-worth. Some research indicated that although self esteem declines during adolescence, females experience a decline more rapidly than males (Heaven, \& Ciarrochi, 2008), with the greatest gender difference reported in late adolescence (Kling, Hyde, Showers, \& Buswell, 1999) and the gap becoming smaller, but still significant, over time. However, other studies have found no gender differences at all in self-esteem (Dixon, \& Kurpius, 2008). Other compelling explanations for gender differences in self-esteem focus on issues related to reflected appraisals and social comparisons.

In spite of these comparisons, female teenagers and women are more than boys or men socially judged based on what they look like. If they diverge from generally constructed cultural ideals of beauty, others may think poorly of them, and through reflected appraisals, their self-esteem may suffer (McMullina, \& Cairney, 2004). In a study conducted by Anderson and Bulik (2004) female undergraduate students expressed higher levels of body dissatisfaction, body image dysphoria and were more invested in their appearance than male under-graduates (Anderson, \& Bulik, 2004). Earlier studies have revealed that self-esteem is strongly and negatively correlated with depression (Rosenberg, Schooler, \& Schoenbach, 1989), and that individuals with high self-esteem coped better with depression (Orth, Robins, \& Meier, 2009). Therefore, with the increasing number of depressed teenagers, scientists and doctors have begun to take seriously the risk of depression among teenagers. In the view 
of Soresi, Nota and Ferrari (2005), childhood and adolescent depression must not be underestimated, as it is associated with dysthymic and anxiety disorders, severe behavioral disorders, and substance abuse.

However, research has also shown that teenage depression often persists, recurs and continues into adulthood, especially if it goes untreated (Kovac, 1996). Given the calamitous effect of depression on teenagers, particularly in inducing or predicting bullying behavior, which earlier studies have revealed was dangerous to both the bullies and their victims. Therefore, efforts need to be made to curtail this development. Though, some studies have used self-esteem as a moderator (Civitci \& Civitci, 2009) however, none of the studies examined the moderating effect of self-esteem in the relationship between depression and bullying like in the present study. In view of this, the current study sought to fill the gap discovered in the literature because neither earlier nor recent studies used self-esteem as a moderator like in the above case.

\section{Hypothesis}

The intention of this analysis was to test the direction of relationship between self-esteem, depression and bullying behavior among teenagers. An important aspect of the present study is the examination of the moderating effect of self-esteem in the relationship between depression and bullying. The study took into cognizance methodological approach and recommendations by Baron and Kenny (1986) in the examination of the relationship between self-esteem, depression and bullying.

Figure1 captures the moderation model of the current study, while figure 2 portrayed the prerequisite or assumptions of the moderation analysis. The present study is distinct from past research in this field in that (a) the data was taken from a large-scale representative sample of teenagers (b) the focus is on bullying, and (c) only normal teenagers were included in the study. For a better understanding of the constructs discussed above, the study sought to respond to the following research hypothesis:

- There is no significant difference between male and female in self-esteem.

- There is no significant relationship between self-esteem, depression, and bullying.

- There is no significant moderating effect of self-esteem in the relationship between depression and bullying.

\section{Materials and Methods}

\subsection{Sample and Procedures}

Two hundred and eighty teenage respondents were eligible for the study. Of this number, 38 were dropped due to an imperfect response. Therefore, the final analysis comprised of 242 teenagers (119 males, 123 females) from rural and urban schools in Selangor Malaysia. Participants were given a questionnaire booklet, which contained all the instruments used in the study. The respondents were $88.84 \%$ Malay, $4.13 \%$ Chinese, $6.20 \%$ Indians and $0.83 \%$ others. The ages ranged from 13 to $16(\mathrm{M}=14.67, \mathrm{SD}=1.27)$. The sampling frame of the study comprised of all daily secondary schools in Selangor, Malaysia. Two schools were randomly selected from the rural schools, while three schools were selected from the urban schools of the state. Total number of schools sampled amounted to five schools. Data for the study was collected within the schools using the cluster-sampling techniques. A trained research assistant administered the battery of instruments that included the measures for self-esteem, depression, and bullying. Data were collected in classrooms during a two-hour period. Participants were given information regarding the research and the voluntary nature of their involvement after having met the research sample criteria. Permission to collect data was granted by the Malaysian Ministry of Education, as required by law.

\subsection{Measures}

Each booklet contained a number of validated scales and demographic questions. Respondents were asked to provide details of their age, gender, number of siblings and other information.

4.2.1 Self-esteem was measured using the Rosenberg Self-Esteem Scale, which has been shown to be valid and reliable. The 10-item Rosenberg Self-Esteem Scale (Rosenberg, 1965) assessed global self-esteem. Example of questions contained in the scale include: "At times I think am no good at all" "I feel I do not have much to be proud of" "I certainly feel useless at times". Each item is rated on a 4-point scale ranging from strongly disagree to strongly agree. The higher the score obtained in the RSE, the greater the levels of self-esteem. The self-esteem scale has been widely used in several studies. The internal consistency of the scale in the present study was 0.67.

4.2.2 Children Depression Inventory (CDI: Kovacs, 1985) is a 27-item Likert-type measure that assesses children's perceptions of the severity of specific cognitive, affective, behavioral and depressive symptoms experienced in the past two weeks. A score of 0,1 , or 2 is given to each item, with a score of 2 representing the most severe choice. The CDI is used with school-age children, and it is the most widely used measure of 
childhood depression (Kazdin, 1990). The 27-item of the CDI range from 0 to 54, with higher scores associated with higher depressive symptoms. Examples of questions contained in the instrument include "I am sad", "Nothing will ever work out for me", "I do everything wrong". Kovac (1985) set a score of 20 as the cut-point for the identification of depressive symptoms in a normal population. Psychometric studies of the CDI have shown high degrees of internal consistency, test-retest reliability, and construct validity in nonclinical populations (Cole, Hoffman, Tram, \& Maxwell, 2000). According to Kovac (1983) the CDI has an acceptable internal consistency, with a Cronbach alpha $(\alpha)$ coefficient of .71. In the current study, the Cronbach alpha $(\alpha)$ was 0.77 .

4.2.3 Bullying was measured using the bully sub scale of the Peer Relationship Questionnaire (Rigley \& Slee, 1993). The PRQ is a self-report questionnaire used to measure bullying, victimization and pro-social behavior among children between the ages of 12 to 18 years. The bully scale consists of six items scored on a 4-point scale, ranging from $1=$ Never, $2=$ Once in a while, $3=$ Pretty often, and $4=$ Very often. The PRQ contains three sub scales, which include: bully scale with six items measuring the tendency to bully others (e. g., I give soft kids a hard time. I like to show others that I'm the boss. I like to make others scared of me). In this study, the internal consistence of the bully scale was found to be acceptable (Cronbach alpha $(\alpha)=.78$ ).

\section{Results}

The data for all the three-research instruments were numerically scored and quantified. Each of these quantitative scores was entered on to a raw data sheet, for each subject and then entered into SPSS version 17 for analysis. Inferential and descriptive statistical tests were performed. Specifically, a regression analysis was applied to determine the moderating role of self-esteem in the relationship between depression and self-esteem. Pearson's product moment correlation was used to determine the direction of relationship between depression, self esteem and bullying. Descriptive statistics were used to calculate means, standard deviation (SD) and range. The interpretation of correlation results was based on a Cohen (1988) guideline which suggested $r=.10$ to .29 Small correlation, $r=.30$ to .49 medium correlation and $r=.50$ to 1.0 large correlation.

Participants of the study range in age from 13 to 16 years $(\mathrm{M}=14.67$ years, S.D $=1.27)$, which comprise of $49.2 \%$ (119) male and 50.8\% (123) female. In the present sample, $87.2 \%$ (211) did not meet the criteria set by Kovac (1985) as depressed, while $12.8 \%$ (31) of the sample met the despair criteria. Of the $12.8 \%$ (31) depressed teenagers, $45.2 \%$ (14) were males, while $54.8 \%$ (17) were females. More so, $61.2 \%$ (148) of the sample reported low self-esteem, while $38.8 \%$ (94) of the sample recorded high self-esteem. Of the $94(38.8 \%)$ with high self-esteem $47(50 \%)$ respectively for both males and females reported high self-esteem. The study further indicated that $123(50.8 \%)$ of the respondents reported none involvement in bullying, as against $49.2 \%$ (119) found to be bullies. Of the $119(48.2 \%$ ) bullies, $56.3 \%$ (67) were males, while $43.7 \%$ (52) were females. Table 1 reveals the independent-sample t-test conducted to compare self- esteem scores for males and females. An inspection of the two means suggested that there is no significant difference $(t=-.166, p>.05)$ in self-esteem scores for males $(\mathrm{M}=28.31, \mathrm{SD}=3.75)$ and females $(\mathrm{M}=28.37, \mathrm{SD}=3.62)$. The study, therefore, suggests that there is no significant gender difference in self-esteem between male and female teenagers.

Table 2 reveals the correlation between measures of self-esteem, depression and bullying behavior. The table suggests a negative and medium correlation between depression and self esteem $(r=-.497, p \leq 01)$ with high self-esteem associated with a lower level of depression. Furthermore, the table further suggested a positive and small correlation between depression and bullying $(r=.296, p \leq .01) 01$ with a high level of depression associated with a high level of bullying. Additionally the table suggested a negative and small correlation between self-esteem and bullying $(r=-.127, p \leq .05) 05$ with low self esteem associated with high levels of bullying. To test moderating effects of self-esteem on the relationships between depression and bullying, hierarchical regression procedures were performed as recommended by Baron and Kenny (1986). Moderating effect is typically expressed as an interaction between the predictor and criterion variables (Barron, \& Kenny, 1986). Moderator analyses were therefore, performed to examine the interactive effects of depression and self-esteem in predicting bullying. Before testing for interaction effects, the continuous-level predictor and moderator were centered by subtracting the mean from both continuous variables (depression and self-esteem).

The centered predictor and moderator terms were multiplied to form the interaction term. Aiken and West (1991) method were used to reduce problems with multicollinearity and to facilitate interpretation of significant interaction effect. In the hierarchical regression model, the order of entry was as follows. At Step 1 and Step 2, the predictor (depression) and moderator (self-esteem) variables were entered sequentially into the regression equations. At Step 3, the interactions of depression $\mathrm{x}$ self-esteem was added. Change in $\mathrm{R}^{2}$ for the interaction term did not indicate significant moderation effect. The results of the final regression model presented in Table 3 , 
revealed that depression $(\beta=.32, \mathrm{p} \leq .001)$ predicted considerably bullying, while self-esteem $(\beta=.03, p>.001)$ did not appreciably predict bullying. In the model, higher depression was associated with greater bullying. However, there was no relevant interaction between depression and self-esteem $(\beta=.04, p>.05)$. These findings revealed that self-esteem had no moderating effect on the relationship between depression and bullying. Since interaction terms were not consequential, regression lines were not plotted.

\section{Discussion and Conclusion}

The article provides an excellent illustration of the diversity of research approaches to the notion of teenage bullying. In line with the first objective of the study, gender differences in self-esteem were examined. Since there were no significant differences in self-esteem despite some available literatures, which suggest same between males and females in self-esteem (Olweus, 1989; O'Moore \& Hillery, 1991) one may say that the results observed here reflects the differences in the way of interpreting the behaviors of the target. The present study, consequently, concluded that the mechanisms underlying this phenomenon may be connected to the cultural norm in the Malaysian society which emphasized integration among teenagers irrespective of their gender. The finding obtained in the study is therefore, commendable given the notion that in most society's female teenagers lagged in self-esteem when compared with their male counterparts (Heaven \& Ciarrochi, 2008). In the view of Diener and Diener (1995), high self-esteem was the strongest factor in overall life satisfaction. In consonance with the second objective of the study, the study confirms the pattern of relationship between the variables examined for the study with earlier studies conducted outside the Malaysian context.

However, the correlation between depression and bullying found in the study suggest that depression is related to bullying and that most bullies exhibited depressive symptom. Nevertheless, given the small correlation between these two constructs, this assertion is rather contestable. Given the findings from the third objective of this study, the present study provided new and convincing empirical evidence, which reveal the failure of self-esteem in reducing the predictive power of depression in cases of bullying. The finding of this study, therefore, emphasizes the role of self-esteem in the increase of depression induced bullying behavior among teenagers. In considering the results of this study, several issues are clear. The present findings provide promising empirical support for our model, though the researcher acknowledges limitations relevant to methodological and sampling issues. Therefore, the interpretation of the findings of this study should be with caution. First, subjects in this study were from Selangor, Malaysia.

Therefore, caution needs to be exercised in generalizing the findings of this study to teenagers. Second, the data in this study were gathered at one point in time. Consequently, the subject' perception may have been influenced by covariate factors. Thus, the interpretation of the results is constrained by the cross-sectional nature of the data. More so, given that the entire instrument used in the study were self-report, respondents may have answered according to their own opinion, thereby affecting the result of the study. Lastly, problems such as difficulty in understanding the Likert-type scale and tiredness of the subjects were encountered in the administration of the instruments. These problems may have affected the scores obtained and thus weaken the validity of the study. Furthermore, the low Cronbach alpha level $\alpha(r=.67)$ for Rosenberg Self-Esteem Scale placed further concern for the reliability of the instrument. Concisely, the study recognizes the need for high self-esteem among teenagers. Sadly, the findings reveal that it takes much more than self-esteem in combating the devastating effect of depression on teenage bullies.

In dealing with depression induced bullying behavior and in line with the above assertion, the current study serves as a base line for researchers and practitioners in teenage care. By advocating other issues, which may reduce depression induced bullying behavior among young bullies. In general, there is an obvious need to carry out further research on other variables besides self-esteem, given that self-esteem was found incapable of reducing the relationship between depression and bullying. Other issues not examined in the current study such as involvement in sports or pious activities may equally be examined because teenagers actively involved in sports and religious pursuits some studies have shown had comparatively lower levels of depression when compared with their uninvolved peers. More so, studies replicating the present study could also be conducted to either confirm or repudiate the findings of the study.

\section{Acknowledgments}

The authors wish to acknowledge Dr. Rigley, Dr. Slee and Dr. Rosenberg for granting the permission to use their measures. The authors would also like to thank all research assistants involved in the collection of the data for the study. 


\section{References}

Aiken, L. S., \& West, S. G. (1991). Multiple regression: Testing and interpreting interactions. New bury Park, CA: Sage.

Anderson, C. B., \& Bulik, C. M. (2004). Gender differences in compensatory behaviors, weight and shape salience, and drive for thinness. Eating Behaviors, 5, 1-11.

Archer, J., \& Cote, S. (2005). Sex differences in aggressive behavior. In Tremblay, R. E., Hartup, W. W., \& Archer, J. (Eds.), Developmental origins of aggression (pp. 425-443). New York: Guilford Press.

Baldry, A. C. (2003). Bullying in schools and exposure to domestic violence. Child Abuse and Neglect, 27, 713-732.

Baron, R.M., \& Kenny, D.A. (1986). The moderator-mediator variable distinction in social psychological research: Conceptual, strategic, and statistical considerations. Journal of Personality and Social Psychology, 51 (6), 1173-1182.

Berger, K.S. (2007). Update on bullying at school: Science forgotten? Developmental Review 27, 90-126.

Boulton, M.J., Trueman, M., Murray, L. (2008). Associations between peer victimization, fear of future victimization and disrupted concentration on class work among junior school pupils. British Journal of Educational Psychology, 78,473-89.

Bowlby, J. (1982). Attachment and loss: Vol. 1. Attachment. New York: Basic Books.

Brame, B., Nagin, D. S., \& Tremblay, R. E. (2001). Developmental trajectories of physical aggression from school entry to late adolescence. Journal of Child Psychology and Psychiatry, 42, 503-512.

Burns, S., Maycock, B., Cross, D., \& Brown, G. (2008). The power of peers: Why some students bully others to conform. Qualitative Health Research, 18(12), 1704-1716.

Civitci, N., \& Civitci, A. (2009). Self-esteem as mediator and moderator of the relationship between loneliness and life satisfaction in adolescents. Personality and Individual Differences, 47, 954-958.

Cohen, J.W. (1988). Statistical power analysis for the behavioral sciences (2nd ed.). Hillside, NJ: Lawrence Erlbaum Associates.

Cole, D. A., Hoffman, K., Tram, J. M., \& Maxwell, S. E. (2000). Structural differences in parent and child reports of children's symptoms of depression and anxiety. Psychological Assessment, 12, 174-185.

Cunningham, N. J., Taylor, M., Whitten, M. E., Hardesty, P.H., Eder, K., \& DeLaney, N. (2010). The relationship between self-perception of physical attractiveness and sexual bullying in early adolescence. Aggressive Behaviour, 36(5), 271-281.

Diener, E., \& Diener, M. (1995). Cross-cultural correlates of life satisfaction and self-esteem. Journal of Personality and Social Psychology, 68, 653-663

Dixon, S. K., \& Kurpius, S. E. R. (2008). Depression and college stress among university undergraduates: Do mattering and self-esteem made a difference? Journal of College Student Development, 49, 412-424.

Espelage, D. L., Meban, S. E., \& Swearer, S. M. (2004). Gender differences in bullying: Moving beyond mean level differences. In Espelage, D.L., \& Swearer, S. M. (Ends.), Bullying in American schools: A social-ecological perspective on prevention and intervention (pp. 15-35). Mahwah, NJ: Erlbaum

Goldbaum, S., Craig, W.M., Pepler, D., \& Connolly, J. (2007). Developmental trajectories of victimization: Identifying risk and protective factors. In: Zins, J.E., Elias, M.J., \& Maher, C.A., (Ends). Bullying, victimization, and peer harassment: A handbook of prevention and intervention. New York, NY: Haworth Press.

Hawker, D. S. J., \& Boulton, M. J. (2000). Twenty years' research on peer victimization and psychosocial maladjustment: A meta-analytic review of cross-sectional studies. Journal of Child Psychiatry and Psychiatry, 41, 441-455

Heaven, P. C., \& Ciarrochi, J. V. (2008). Parental styles, conscientiousness, and academic performance in high school: A three-wave longitudinal study. Personality and Social Psychology Bulletin, 34, 451-461.

Ivarsson, T., Broberg, A G., Arvidsson, T., \& Gillberg, C. (2005). Bullying in adolescence: Psychiatric problems in victims and bullies as measured by the youth self report and the depression self-rating scale. Nord Journal of Psychiatry, 59,365-373. 
Kazdin, A. E. (1990). Assessment of childhood depression. In A. M. LaGreca (Ed.), Through the eyes of the child: Obtaining self-reports from children and adolescents (pp. 189-233). Boston: Allyn \& Bacon.

Kling, K. C., Hyde, J. S., Showers, C. J., \& Buswell, B. N. (1999). Gender differences in self-esteem: A meta-analysis. Psychological Bulletin, 125, 470-500.

Kovac, M. (1985). The children's depression inventory. Psychopharmacology Bulletin, 21, 995-998.

Kovac, M. (1983). The Children's Depression Inventory: A self rated depression scale for school aged youngsters. Unpublished manuscript, University of Pittsburgh School of Medicine.

Kovacs, M. (1996). The course of childhood-onset depressive disorders. Psychiatric Annuals, 26, 326-330.

Main, M., Kaplan, N., \& Cassidy, J. (1985). Security in infancy, childhood, and adulthood: A move to the level of representation. In Bretherton, I., \& Waters, E. (Eds.), Growing points of attachment theory and research. Monographs of the Society for Research in Child Development, 50, 1-2.

McMullina, J. A., \& Cairney, J. (2004). Self-esteem and the intersection of age, class, and gender. Journal of Aging Studies 18, 75-90

Monks, C. P., Smith, P. K., \& Swettenham, J. (2005). The psychological correlates of peer victimization in preschool: Social cognitive skills, executive function and attachment profiles. Aggressive Behavior, 31, 571-588.

Monks, C.P., Smith, P.K., Naylor, P., Barter, C., \& Ireland, J. L. et al. (2009). Bullying in different contexts: Commonalities, differences and the role of theory. Aggression and Violent Behavior, 14, 146-156.

Olweus, D. (1989). Bully/victim problems among school children: Basic facts and effects of a school-based intervention program. In K Rubin \& D. Pepler (Eds.). The development and treatment of childhood aggression (pp. 411-448). Hillsdale, NJ: Erlbaum.

O'Moore, A. M., \& Hillery, B. (1991). What do teachers need to know? In Elliott, M. (Ed.), Bullying: A practical guide to coping for schools (pp. 56-69). Harlow, U.K.: Longman Group.

Orth, U., Robins, R.W., \& Meier, L.L. (2009). Disentangling the effects of low self-esteem and stressful events on depression: findings from three longitudinal studies. Journal Personal Social Psychology, 97(2), 307-21.

Perlin, L. I., Lieberman, M. A., Menaghan, E. B., \& Mullan, J. T. (1981). The stress process. Journal of Health and Social Behavior, 22, 337-356.

Richardson, T. M., \& Benbow, C. P. (1990). Long-term effects of acceleration on the social-emotional adjustment of mathematically precocious youths. Journal of Educational Psychology, 82, 464-470.

Rigley, K., \& Slee, P.T. (1993). Dimensions of interpersonal relating among Australian school children and their implications for psychological well-being. Journal of Social Psychology, 133(1), 33-42.

Roberts, C. M., Kane, R., Bishop, B., Cross, D., Fenton, J., \& Hart, B. (2010). The prevention of anxiety and depression in children from disadvantaged schools. Behaviour Research and Therapy, 48, 68-73.

Rosenberg, I. (1965). Society and Adolescent Self Image. Princeton University Press, New Jersey.

Rosenberg, M., Schooler, C., \& Schoenbach, C. (1989). Self-esteem and adolescent problems: Modeling reciprocal effects. American Sociological Review, 54, 1004-1018.

Scarpa, A., \& Luscher, K.A. (2002). Self-esteem, cortisol reactivity, and depressed mood mediated by perceptions of control. Biological Psychology, 59, 93-103

Soresi, S., Nota, L., \& Ferrari, L. (2005). Counseling for adolescents and children at-risk in Italy. Journal of Mental Health Counseling, 27 (3), 249-265.

Spriggs, A.L., Iannotti, R. J., Nansel, T. R., \& Haynie, D.L. (2007). Adolescent bullying involvement and perceived family, peer and school relations: Commonalities and differences across race/ethnicity. Journal of Adolescent Health 41, 283-293.

Stauffacher, K., \& DeHart, G. B. (2006). Crossing social contexts: Relational aggression between siblings and friends during early and middle childhood. Applied Developmental Psychology, 27(3), 228-240.

Twemlow, S. M., \& Fonagy, P. (2005). The prevalence of teachers who bully students in schools with differing levels of behavioral problems. American Journal of Psychiatry, 162, 2387-2389.

Uba, I., Siti Nor Y., \& Rumaya, J. (2009). The The relationship between peer relations and depression among adolescents in Selangor, Malaysia. European Journal of Social Sciences, 11(1), 149-159. 
Yaakub, N. F., \& Leong, G. C. (2007). Violence in schools: Moving forward. http://www.unicef.org/malaysia/protection_6930.html. Assessed on Tuesday, 28th October, 2008.

Table 1. Comparison of Mean Scores for Male and Females in Self-esteem

\begin{tabular}{|lllllllll|}
\hline Scales & $\mathbf{n}$ & Mean & SD & SE & Df & MD & t & $\boldsymbol{P}$ \\
\hline Self-esteem & & & & & & & & \\
Male & 119 & 28.31 & 3.75 & 0.34 & & & & \\
Female & 123 & 28.37 & 3.62 & 0.33 & 240 & -.05 & -.166 & .908 \\
\hline
\end{tabular}

Note: $\mathrm{SD}=$ Standard deviation; $\mathrm{SE}=$ Standard Error; $\mathrm{df}=$ Degree of Freedom; $\mathrm{MD}=$ Mean Difference.

Table 2. Correlations between self-esteem, depression, gender and bullying

\begin{tabular}{|llll|}
\hline Variables & $\mathbf{1}$ & $\mathbf{2}$ & $\mathbf{3}$ \\
\hline 1. Depression & 1 & & \\
2. Self esteem & $-.497^{* *}$ & 1 & \\
3. Bullying & $.296^{* *}$ & $-.127^{* *}$ & 1 \\
4. Gender & -.032 & .007 & $-.210^{* *}$ \\
& & & \\
M & 13.29 & 28.34 & 9.42 \\
SD & 5.95 & 3.68 & 3.25 \\
Min & 0 & 18.00 & 6.00 \\
Max & 31 & 38.00 & 21.00 \\
$\alpha$ & .77 & .67 & .78 \\
& & & \\
\hline
\end{tabular}

Correlation is significant at the 0.01 level (2-tailed)

Correlation is significant at the 0.05 level (2-tailed)

Table 3. Hierarchical regression analysis for moderating effect of self-esteem on the relationships between depression bullying

\begin{tabular}{|lccccccc|}
\hline Variables & B & SEB & $\boldsymbol{B}$ & $\boldsymbol{R} 2$ & R2 Change & F Change & Sig \\
\hline $\begin{array}{l}\text { Dependent Variable: Bullying } \\
\text { Step 1 }\end{array}$ & & & & & & & \\
$\begin{array}{l}\text { Depression } \\
\text { Step 2 }\end{array}$ & .175 & .040 & .319 & .088 & .088 & 23.05 & .000 \\
$\begin{array}{l}\text { Self-esteem } \\
\text { Step 3 } \\
\text { Depression x Self-esteem }\end{array}$ & .023 & .063 & .026 & .088 & .001 & .142 & .716 \\
\hline
\end{tabular}

Note: $\mathrm{B}, \mathrm{SEB}$, and $\mathrm{b}$ reflect values from the final regression equation. ${ }^{*} p<.001$. 


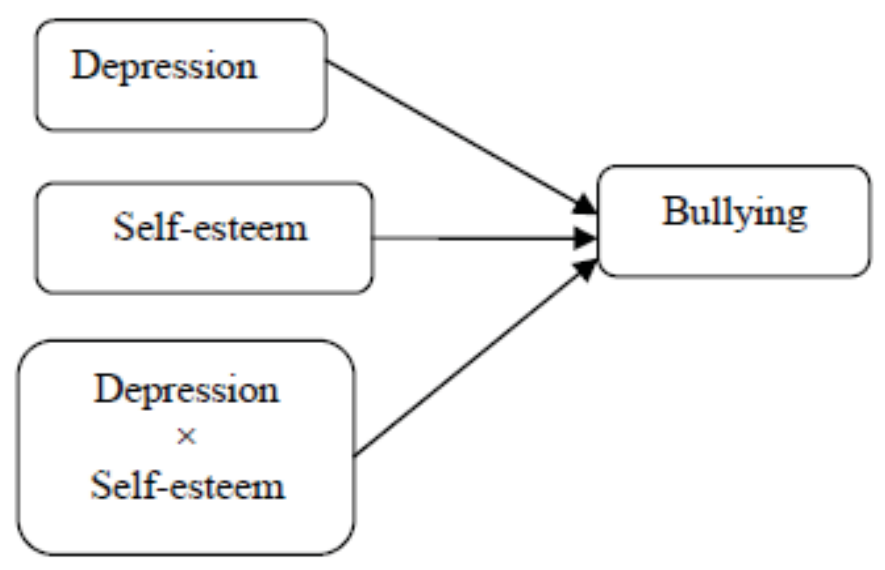

Figure 1. Moderation model

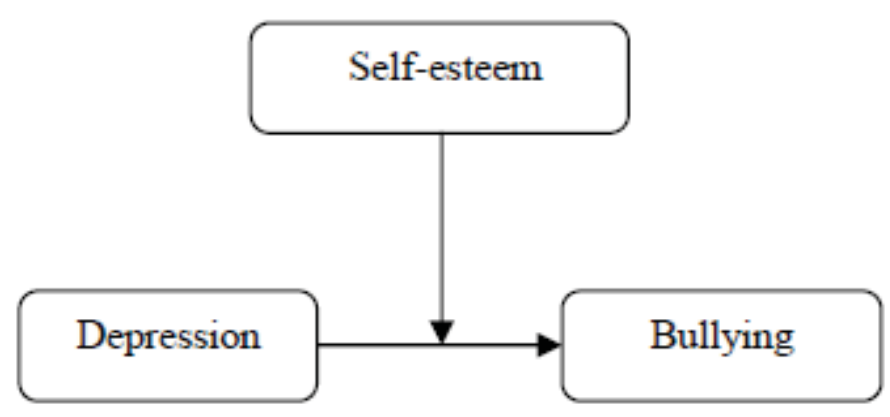

Figure 2. Moderation assumption 